\title{
Análise de Publicações 'Terraplanistas' em Rede Social: Reflexões para o Ensino de Ciências sob a Ótica Discursiva de Foucault
}

\author{
Analysis of 'Flat-Earther' Posts on Social Media: Reflections \\ for Science Education from the Discursive Perspective of \\ Foucault
}

\author{
Leonardo Wilezelek Soares de Melo ${ }^{\circledR}$ Brasil \\ Marinez Meneghello Passos ${ }^{\circledR}$ Brasil \\ Rosana Figueiredo Salvi ${ }^{\circledR}$ Brasil
}

Neste artigo apresentamos os resultados de uma pesquisa que objetivou analisar publicações da página do Twitter de uma organização que defende abertamente que a Terra é plana e evidenciar quais são suas características formativas, bem como discutir sobre quais seriam as possíveis implicações de tal defesa para o Ensino de Ciências. A análise do discurso foi realizada a partir dos encaminhamentos apresentados por Foucault e como teorias a priori foram tomadas contribuições de Feyerabend, Latour e Stengers. Essas escolhas ocorreram pelo fato de esses aportes apresentarem pontos de vista heterodoxos sobre a produção dos conhecimentos científicos, abertos a implicações que não são apenas epistemológicas, o que possibilita discutir a complexidade cultural, social e discursiva da crença no 'terraplanismo'. Espera-se que as considerações aqui apresentadas possam promover discussões relacionadas à temática por parte daqueles que atuam no Ensino de Ciências e, ainda, reflexões relativas à própria ética do processo científico e de seus limites.

Palavras-chave: redes sociais; Terra plana; análise do discurso.

In this paper we present the results of a research that aimed to analyze posts on a Twitter page of an organization that openly defends that the Earth is flat and to highlight its formative characteristics, as well as to discuss about the possible implications of such defense for Science Education. Discourse analysis was carried out based on the guidelines presented by Foucault and a priori theories were taken from the contributions of Feyerabend, Latour and Stengers. These choices occurred due to the fact that these contributions present heterodox points of view on the production of scientific knowledge, open to implications that are not only epistemological, which makes it possible to discuss the cultural, social and discursive complexity of the 'flat Earth belief'. It is hoped that the 
considerations presented here may promote discussions related to the theme on the part of those who work in Science Education and, also, promote reflections on the very ethics of the scientific process and its limits.

Keywords: social media; flat Earth; discourse analysis.

\section{Introduzindo a pesquisa}

Em tempos de pós-verdades (Dunker et al., 2017), consensos científicos, outrora considerados indiscutíveis e pétreos, são colocados em xeque por certos grupos e instituições, por meio de dinâmicas de propagação conhecidas como teorias da conspiração. Essas têm ganhado cada vez mais espaço nas discussões e pautas dos mais diversos campos de conhecimento, cenário que nos mobilizou a investigar a ação de um desses fenômenos em expansão. Por isso, neste artigo, trazemos os resultados de um primeiro movimento que destaca as nuances implicativas de uma de suas vertentes - a hipótese de que a Terra é plana - para o Ensino de Ciências.

Tal conjuntura conduziu-nos a descrever, mesmo que resumidamente, alguns pormenores sobre essas teorias - da conspiração - (que sustentam discursos de forma multidisciplinar), perpassando pela Psicologia, Psiquiatria, Comunicação, Linguística, Antropologia e, até mesmo, a Filosofia da Ciência. Diante desta delimitação, consideramos como teoria da conspiração qualquer narrativa ou enredo que acuse que certos grupos de pessoas ou organizações, na maioria das vezes poderosas e em alguns casos misteriosas, ao que parece, reúnem-se para trabalhar, de maneira secreta, em prol de objetivos usualmente malévolos (Goertzel, 1994; Wood, Douglas, \& Sutton, 2012; Swami et al., 2014; Prooijen, 2017). Contudo, tal definição não é suficiente e nem fechada em si mesma, já que há uma multiplicidade de discursos que podem ser julgados por conspiratórios e carregam consigo suas próprias particularidades.

Dentre os diversos 'tipos' existentes de teorias consideradas de conspiração, podem ser elencadas, dentre outras: aquelas decunho político-internacional, como as que discutem fatores suspeitos envolvendo o ataque de 11 de setembro de 2001, as mortes de John Kennedy, Princesa Diana ou Bin Laden (Harambam, \& Aupers, 2014); as de cunho socioeconômico, relativasàmigraçãodedeterminadosgruposétnicosparapaíseseuropeus ou os Estados Unidos da América e a dominação das elites poderosas em países latino-americanos (Silva, Vegetti, \& Litvayy, 2017); as que abrangem boatos relacionados à Ciência e Tecnologia, dentre as quais se destacam as que alegam que vacinas causam autismo, as que defendem que mudanças climáticas não passam de boataria enganosa (Jolley, \& Douglas, 2014), ou mesmo as que consideram que a Terra é plana (Prooijen, \& Douglas, 2018).

Cada vez mais crescentes e dispersas pela sociedade, potencializadas com o advento das mídias digitais e das redes sociais, as estratégias para compreender ou lidar com essas teorias conspiratórias e controversas têm sido majoritariamente reativas, concentrando-se em rotular e oprimir esses discursos, defendendo imposições políticas, 
sociais e econômicas aos grupos que os sustentam. Além disto, pouco se tem pensado proativamente sobre a temática, sendo majoritárias as posições que intentam modificar tais comportamentos e atitudes de negação da Ciência, tomando-se por fundamento os próprios conhecimentos científicos e seus padrões de racionalidade, como discutido por Browne et al. (2015), sendo minoritárias as tentativas de conceber tal fenômeno em sua complexidade cultural e discursiva.

Considerando essa problemática, debruçamo-nos sobre as publicações da página oficial do Twitter de uma organização que defende abertamente que a Terra é plana, tendo por aporte teorias de análise qualitativa para analisar o discurso: as contribuições teóricas de Foucault (1996). Ampliando tal estrato, trazemos também discussões a respeito das possíveis implicações desse discurso para o Ensino de Ciências (nossa área de atuação), bem como sobre sua estruturação e suas características, tomando como teorizações para análise as contribuições de Feyerabend $(1977 ; 2010)$ e dos Estudos Sociais de Ciências, a partir das discussões promovidas por Latour (2004; 2011) e Stengers (2015). Tais pontos de vista, em termos de Filosofia e de Sociologias das Ciências, foram considerados coerentes para com os objetivos aqui ensejados, em se tratando de suas críticas à ortodoxia científica e à racionalidade estrita, no caso do primeiro autor, e aos próprios modos de produção de fatos científicos, no caso dos demais.

Diante de tal propósito, dois questionamentos foram considerados norteadores e podem ser assim revisitados: Sob essas óticas, que compreensões puderam ser demonstradas do discurso evidenciado nas publicações do Twitter analisadas, consideradas 'conspiracionistas' e que alegam que a Terra é plana? Que posicionamentos a área de Ensino de Ciências poderia arregimentar frente a esses discursos?

Para proceder com as argumentações propostas, as discussões foram estruturadas nos quatro tópicos seguintes: abordagem das principais ideias sobre o que tem levado as pessoas a acreditarem em teorias da conspiração como a de que a Terra é plana; apresentação de métodos empregados na pesquisa e os referenciais que os sustentam; apresentação e análise dos dados da investigação coletados na página do Twitter da organização que defende a teoria 'terraplanista'; e considerações obtidas após as análises e reflexões estruturadas, discutindo-se sobre as impressões concebidas referentes aos discursos que evocam que a Terra é plana e os caminhos que a análise desses discursos evidencia em relação à Ciência e seu ensino.

\section{Uma questão complexa: por que se acredita em teorias da conspiração?}

Antes de se construir uma discussão em relação à questão que intitula esta seção, é preciso salientar que teorias da conspiração não são necessariamente falsas por definição (Wood, Douglas, \& Sutton, 2012), sendo muitas vezes originárias da capacidade analítica de sujeitos de inferir com criticidade em determinadas ações políticas ou governamentais e pela assimetria existente nas relações de poder na sociedade (Pelkmans, \& Machold, 2011). Em certos casos, podem até gerar consequências sociais vantajosas, como incitar 
os cidadãos a serem mais questionadores de seus políticos e governantes, acarretando maior transparência governamental (Douglas et al., 2016). Essas ressalvas precisam ficar bem demarcadas neste contexto de discussão, sem que com isso se defenda que essas teorias sejam coerentes ou plausíveis. Isto nos leva a sustentar que não deve haver uma única e conclusiva resposta que possa explicar o que tem levado as pessoas a acreditarem em teorias conspiratórias.

Dito isso, alguns posicionamentos podem ser apresentados. Prooijen e Douglas (2018) destacam quatro possíveis princípios básicos para o aceite dessas teorias: consequencial; universal; emocional; social. O primeiro fundamenta que mesmo que uma teoria conspiratória seja ingênua ou supostamente difícil de acreditar, a simples crença na mesma pode impactar na saúde, nos relacionamentos e na segurança das pessoas, uma vez que pode induzir comportamentos reais, tal como a não adesão à vacinação. $O$ segundo - universal - sugere que não há dimensão histórica ou cultural específica para as crenças em teorias da conspiração, pois todos podem estar suscetíveis a elas, aceitando-se até mesmo que isto seja uma característica da natureza humana. O terceiro princípio - emocional - indica que a crença em conspirações pode estar associada a processos mentais intuitivos e não analíticos enraizados, possivelmente, por emoções negativas e por pensamentos automáticos. O quarto - social - defende que a crença em conspirações é um fenômeno social, já que não envolve apenas um indivíduo, mas em geral um coletivo que compartilha muitas vezes o mesmo temor para com determinada organização ou grupo social.

Sobre esse último princípio, Wood, Douglas e Sutton (2012) discorrem que, mesmo que uma determinada teoria conspiratória seja contraditória em relação a outra qualquer, ainda assim as pessoas podem acreditar concomitantemente nas duas, sem enxergar a possibilidade de uma incoerência. O que pode ser explicado pelo fato de que o que aproxima tais crenças não é, necessariamente, uma ligação entre as teorias em si, mas entendimentos de ordem superior no que se refere a elas, como sentimentos de desconfiança em relação a autoridades ou governos, que estão no centro discursivo e que conectam diversas dessas crenças conspiratórias.

Analogamente a isso, Prooijen (2015) discute que crenças conspiratórias podem surgir de processos psicológicos subjacentes semelhantes e ser influenciadas por dois fatores complementares, denominados "incerteza subjetiva e preocupação social com os outros" (p. 267). O primeiro estaria relacionado à existência de um sentimento de incerteza marcante para com certos eventos muitas vezes complexos, o que incita o sujeito a promover processos que o auxiliem na compreensão desses. Isto estaria coerentemente alinhado à ideia de que tais crenças florescem usualmente após eventos de grande impacto social, sendo os processos envolvidos na proposição dessas teorias um meio de colocar ordenamento e previsibilidade nas percepções sobre os acontecimentos. Por outro lado, o segundo estaria relacionado ao apoio aos grupos afetados por algum desses eventos de grande impacto, apoio este justificado em face às supostas ou possíveis investidas dos "poderosos" que estariam por trás desses eventos, mediante tais teorias. 
Prooijen (2015) remarca, nesse sentido, que fortes sentimentos de inclusão coletiva podem ser característicos de certas crenças conspiratórias.

Douglas et al. (2016) apontam que a crença em teorias da conspiração pode estar associada ao modo com que as pessoas percebem o mundo à sua volta e em como lidam com eventos que lhes aparentam ser incertos ou obscuros. Isso pode estar relacionado à tendência de determinadas pessoas (ou grupos) de atribuir intencionalidade e ação a casos em que é improvável que essas existam, tal como ocorre nos julgamentos automáticos em relação à ocorrência de certos fenômenos que parecem sobrenaturais. Nestes casos, a visão é de que essa não é uma tendência necessariamente negativa, já que pode ter raízes na própria evolução do ser humano, que sempre precisou mostrarse apto a reagir de maneira rápida às situações ambíguas e estranhas, provenientes do ambiente à sua volta, fator que foi importante para a sobrevivência tanto física quanto social da espécie.

Aliado ao que discutem esses autores, Prooijen (2017) aponta que pessoas com maiores níveis educacionais são, em tese, menos suscetíveis a acreditar em teorias conspiratórias, embora isso deva ser sustentado com bastante cuidado. Pois a relação entre nível educacional e crença em conspirações é "produto de uma interação complexa de múltiplos processos psicológicos" (Prooijen, 2017, p. 56). Assim, até mesmo sentimentos de impotência social perante o contexto vivido podem implicar no aceite dessas teorias, não devendo ser essa relação defendida de maneira simplista e tampouco como uma motivação válida para que se possa questionar ou, ainda, interferir nas crenças dessas pessoas.

Uma característica comum a todas as teorias da conspiração, mesmo no caso das notadamente inverídicas, é sua tendência de resistirem às tentativas de falsificação propostas por seus críticos. Nesses parâmetros, conspirações podem se constituir como "programas degenerativos de pesquisa” (Wood, Douglas, \& Sutton, 2012, p. 767), em que seus "teóricos" apelam a novas evidências conspiratórias, que são adicionadas à teoria original, de modo a validar suas intenções e, por conseguinte, reafirmá-las.

Essa resistência à impugnação por parte dos seguidores de teorias conspiratórias permite inferir que posturas sempre julgadoras ou denunciantes em relação a seus adeptos podem não surtir efeito algum no sentido de desencorajá-las, já que os rótulos colocados pelos críticos são usualmente mais efetivos em denegrir as pessoas consideradas como 'conspiracionistas' do que as teorias em si. Além disso, por outro lado, tais posturas acusatórias podem mesmo reafirmar essas crenças e estimular seus caudatários a questionarem se, na realidade, tais teorias não estariam atuando em uma direção correta (Wood, 2016).

Isso pode ser corroborado pelas discussões realizadas por Browne et al. (2015), que questionam a efetividade de medidas pautadas na racionalidade científica, bem como no raciocínio baseado em evidências, entre elas as estratégias majoritárias para tratar de posicionamentos de negação da Ciência. Tais medidas não levariam em conta um fator importante estudado pela Psicologia Cognitiva: "Os seres humanos são processadores 
de informação tendenciosos e, frequentemente, envolvem-se em raciocínio motivado" (Browne et al., 2015, p. 01). Isso permite hipotetizar que fatores emocionais e sociais podem ser mais determinantes sobre o raciocínio humano e sobre as tomadas de decisão cotidianas, impondo certos preconceitos imprecisos e vieses heurísticos que não seriam, por obrigação, passíveis de mudança apenas pela apresentação de fatos e evidências empíricas comprovadas pela Ciência, o que denota a complexidade cultural atrelada a essas crenças.

É nesse sentido que emerge a nossa curiosidade e o nosso senso investigativo por compreender os discursos, presentes em publicações de uma página do Twitter, considerada conspiracionista e que abertamente defende a hipótese de que a Terra é plana. Por isso, buscamos ir além de sua estrutura linguística e textual, analisando seu caráter discursivo como prática, tal como assume Foucault (1996), de modo a abranger suas regularidades intrínsecas e definir as redes conceituais que lhes são próprias.

Cabe destacar que, por meio dessa ótica discursiva, não há verdades por trás dos discursos aguardando a revelação de um analista, mas sim enunciados e articulações colocados em prática pelo próprio discurso. Propomos que assumir essa conjuntura pode auxiliar no entendimento da complexidade cultural atrelada a discursos conspiracionistas como o da Terra Plana, que podem ter sua emergência e difusão associadas a questões que vão além de suas teorizações, bem como de supostas demandas por racionalidade por parte de seus caudatários. No tópico seguinte, delineamos os encaminhamentos metodológicos que assumimos para proceder com esta investigação.

\section{Os métodos em ação}

Neste processo de pesquisa, procurou-se investigar a página do Twitter da organização internacional Flat Earth Society, que produz e compartilha conteúdo embasado e sustentado na teoria conspiratória de que a Terra é plana, e que apresenta atualmente - considerando o ano de 2020 - milhares de seguidores, sendo a página mais acessada sobre o tema, segundo resultados de pesquisa relacionados à temática no Twitter. O conteúdo dos tweets da página é bastante diverso, abrangendo desde imagens e "memes" referentes à teoria da Terra Plana até a divulgação de conteúdos e eventos relacionados a essa teoria, além de críticas variadas ao conhecimento científico moderno.

Para a delimitação do $\operatorname{corpus}^{1}$ da pesquisa, inicialmente foi selecionado o conteúdo relativo a um ano de postagens da página, entre os meses de maio de 2018 e maio de 2019, coletando-se apenas os posts com conteúdos produzidos pelo próprio perfil da Flat Earth Society e excluindo-se aqueles que fossem produzidos por outros perfis ou pessoas e que eram apenas replicados pela página da organização.

$\mathrm{Na}$ sequência, foram descartadas aquelas postagens que não continham informações consideradas relevantes para os objetivos de analisar o discurso dos 'terraplanistas', entre eles tweets que continham saudações, ou que compartilhassem

1 "[...] o conjunto dos documentos tidos em conta para serem submetidos aos procedimentos analíticos" (Bardin, 2011, p. 126). 
informações que não tratavam de modo explícito da teoria da Terra Plana em seu conteúdo. Essas delimitações iniciais e descartes permitiram reunir um total de 20 tweets, que incluíam textos e frases, alguns diálogos com outros perfis e pessoas, além dos "memes" sobre a temática. Desses 20 tweets, por fim, foram descartadas as postagens que fizessem algum tipo de referência a outros perfis ou pessoas, pois nesses casos desencadeavam-se discussões mais amplas e diversas, envolvendo atitudes e pontos de vista não necessariamente relacionados às hipóteses da Terra Plana - inclusive a emergência de ataques pessoais entre os perfis.

Após essas delimitações, restaram então 8 tweets, interpretados a partir de análise de discurso, segundo Foucault (1996). Para este autor, a produção do discurso "é ao mesmo tempo controlada, selecionada, organizada e redistribuída por certo número de procedimentos que têm por função conjurar seus poderes e perigos, dominar seu acontecimento aleatório, esquivar sua pesada e temível materialidade" (Foucault, 1996, p. 08). Em outras palavras, todo discurso é produzido a partir de relações de poder. Nessa conjuntura, "o discurso não é simplesmente aquilo que traduz as lutas ou os sistemas de dominação, mas aquilo porque, pelo que se luta, o poder do qual nos queremos apoderar" (Foucault, 1996, p. 10).

Nessa conjuntura, como destacado por Fischer (2001), "tudo é prática em Foucault" (p. 200), e tudo está mergulhado em relações de poder e saber. É nesse sentido que o discurso ultrapassa sua utilização como mera expressão de coisas e consolidase como uma rede conceitual com características próprias. A formação de conceitos, portanto, não estaria na consciência dos indivíduos, seguindo padrões de racionalidade, mas no próprio discurso, e as regras da formação discursiva "se impõem a todos aqueles que falam ou tentam falar dentro de um determinado campo discursivo" (Foucault, 1986, p. 70). Essa perspectiva foi considerada coerente para se analisar o contexto da controvérsia na qual se inserem as conspirações, que buscam opor-se aos conhecimentos científicos estabelecidos a partir da elaboração de hipóteses discordantes e, em até certo ponto, hostis à Ciência moderna e à sua hierarquia institucional, ainda que, para tal dissonância, partam de ideias muitas vezes inconsistentes e ilógicas.

Essa peculiaridade do discurso, conforme Foucault (1996), e em nosso âmbito de discussão, pode ser relacionada às argumentações promovidas por Feyerabend (1977; 2010) em relação à busca, por parte de cientistas, pela universalização das regras que constituiriam o método científico, ação que, segundo o autor, pode se consolidar como uma espécie de dogmatismo, que cumpriria a função de legitimar o processo científico e desqualificar ideias que não estariam alinhadas a seus pressupostos. Se, para Foucault (1996), o discurso é uma prática imersa em relações de poder e saber, e que se institui para todos os que participam de determinado processo discursivo, para Feyerabend (2010), os cientistas buscariam universalizar as regras que constituem o método científico - e que, em suma, constituem seu discurso -, utilizando, para tal, todos os meios e ferramentas possíveis, tais como "argumento, propaganda, táticas de pressão, intimidação, ação de grupos" (Feyerabend, 2010, p. 341), de modo a reiterar sua força na sociedade, minando 
outras formas de conhecimento que não compactuem com suas ponderações.

Sem embargo, no contexto das conspirações, essa relação torna-se um tanto quanto mais enredada, já que, nessa conjuntura, os discursos conspiracionistas, como já apresentado, têm se consolidado a partir da desconfiança generalizada em relação à Ciência, apontando para uma suposta trama mundial e malévola, da qual Ciência, pesquisadores, setores da indústria e governos fariam parte. Segundo alegam essas conspirações, tais agentes teriam o suposto intuito de ludibriar e controlar as pessoas e a sociedade (Prooijen, \& Douglas, 2018). Contudo, diferentemente do que poderíamos esperar, esses conspiracionistas, ao invés de desistirem da controvérsia, ou de aderirem às proposições científicas, como remarcaria Latour (2011), têm se mantido firmes em sustentá-las, mesmo que destituídos de força discursiva frente à potência representativa da Ciência e ridicularizados pela mídia, por instituições e pelo público em geral.

O que nos move em termos metodológicos é discutir sobre o que poderia estar mantendo conspiracionistas firmes em efervescer os revisionismos que insistem em nutrir - mesmo que contra dados e expectativas. Seria essa insistência por negação à Ciência um produto do próprio dogmatismo passado de uma Ciência autoritária, tanto discutida por Feyerabend (1977), e que, por tanto ter se concentrado em universalizar seus métodos e regras, se esqueceu daqueles que não os compreenderiam ou os resignariam? Ou seria esse um fenômeno incongruente em relação às críticas promovidas por Feyerabend (1977) à ortodoxia científica, e que demandaria novos olhares para além da epistemologia - mesmo a heterodoxa?

Para mais do que suspeitar, procuramos conduzir uma análise que não tivesse por princípio efetuar meros julgamentos teóricos frente às manifestações discursivas 'terraplanistas', nem de antemão qualificá-las como alienadas ou até mesmo insanas e bizarras em algum sentido - ainda que seja tentador fazê-lo. Para além de julgamentos ou prognósticos, buscamos, a partir dos aportes metodológicos assumidos, uma compreensão desses fenômenos em sua complexidade cultural e discursiva, sendo a perspectiva discursiva de Foucault (1996) convidativa nesse sentido.

Cabe destacar, neste momento, que existem certos princípios de exclusão social atrelados à produção de discursos na sociedade, considerados por Foucault (1996), que podemos trazer à tona para seguir com nossos intuitos. Conforme discute o autor, tratase dos sistemas: da palavra proibida; da segregação da loucura; e da vontade de verdade, sendo os dois últimos de maior valia para nossos fins investigativos.

Como aponta Foucault (1996), a segregação da loucura, usual na Idade Média, como marcador social de impedimento e de desqualificação de discursos, ainda se faz presente, decorrendo, hoje, por outros meios, por outras instituições e produzindo outros efeitos, mas com o mesmo intuito de separação entre o discurso que deve ser considerado aceitável e o que deve ser cessado e qualificado como indesejável. Já a vontade de verdade transcorre da fluidez à qual a noção de verdade se organiza, e que é sustentada, quase sempre, a partir de certo grau de pressão e de violência. Quando se analisa o processo de institucionalização do que é considerado verdadeiro no curso 
da história, demarca-se que, para o autor, não está em questão uma discussão sobre o que são ou não o real e o verdadeiro, mas apenas os meios e modos pelos quais eles se consolidam.

O que intentamos com essa ótica teórica é evitar a exclusão imediata do discurso 'terraplanista', sem antes compreender seus termos, sua formação e sua própria complexidade.

Talvez o grande desafio de uma perspectiva como essa resida em como proceder para se compreender o fenômeno das conspirações de maneira simétrica, tal qual sustentando pelos Estudos Sociais de Ciência e Tecnologia, sem a promoção de juízos depreciativos, e, ao mesmo tempo, sem que se pareça estar considerando suas teorizações potencialmente confiáveis. Essa perspectiva de simetria, que Stengers (2015) apresenta como o ato de não qualificar vencedores e vencidos antes do término de uma controvérsia, pode causar certo desconforto quando se avalia, a partir de uma ótica epistemológica ortodoxa, um contexto tão polêmico, como é o caso das conspirações. Entretanto, ele é congruente com o intento de dissertar sobre essa controvérsia sem acabar constituindo o dogmatismo científico do qual tanto alertara Feyerabend (1977), e ainda, sendo coerente com a perspectiva de discurso de Foucault (1996).

Sob esses parâmetros, portanto, é que analisamos os dados obtidos da página da Flat Earth Society, e que são apresentados e debatidos na seção seguinte.

\section{Os dados e suas evidências}

Os tweets selecionados que constituem o corpus da análise estão dispostos na Figura 1, na primeira coluna. Para representar cada tweet, criamos um código iniciado com a letra $\mathrm{T}$ acompanhada de um número que está relacionado à disposição do tweet no quadro - segunda coluna. Desta forma, o tweet 1 foi representado como T1, o tweet 2 como T2 e assim por diante. Além disso, foi apresentada a data de publicação do discurso pela página - coluna 3 - e sua tradução - coluna 4. A discussão não se deu necessariamente conforme a cronologia dos tweets na Figura 1, mas considerando-se a pertinência desses para o momento argumentativo.

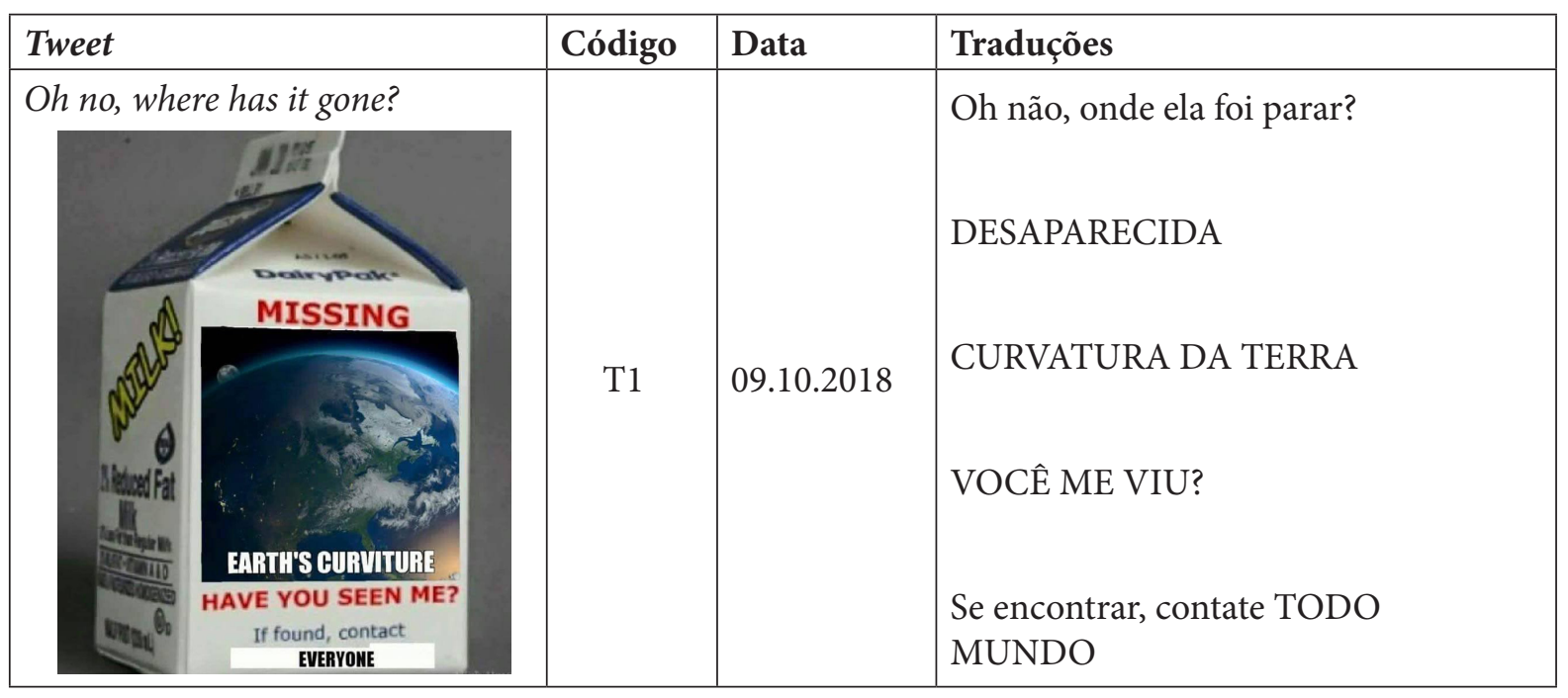

Figura 1. O corpus analítico (continua) 


\begin{tabular}{|c|c|c|c|}
\hline Tweet & Código & Data & Traduções \\
\hline $\begin{array}{l}\text { \#EverybodyShouldGet informed } \\
\text { on the simple fact that the Earth } \\
\text { is flat }\end{array}$ & $\mathrm{T} 2$ & 23.10 .2018 & $\begin{array}{l}\text { \#TodomundoDeveriaSer informado sobre o } \\
\text { simples fato de que a Terra é plana }\end{array}$ \\
\hline $\begin{array}{l}\text { The Earth is not round. } \\
\text { \#StartOverIn } 5 \text { Words }\end{array}$ & $\mathrm{T} 3$ & 23.10 .2018 & $\begin{array}{l}\text { A Terra não é redonda. } \\
\text { \#RecomeçarEm5Palavras }\end{array}$ \\
\hline $\begin{array}{l}\text { Ah, the smell of indoctrination in } \\
\text { the morning! } \\
\text { These are children who struggle } \\
\text { to spell the word "think", but } \\
\text { they've already been told what to } \\
\text { think. } \\
\text { After all, we wouldn't want them } \\
\text { to think for themselves. That } \\
\text { would be bad, wouldn't it? }\end{array}$ & $\mathrm{T} 4$ & 19.11.2018 & $\begin{array}{l}\text { Ah, o cheiro de doutrinação pela manhã! } \\
\text { Estas são crianças que lutam para soletrar } \\
\text { a palavra "pensar", mas elas já foram } \\
\text { informadas sobre o que pensar. } \\
\text { Afinal, não queremos que elas pensem por } \\
\text { si mesmas. Isso seria ruim, não seria? }\end{array}$ \\
\hline & T5 & 11.12 .2018 & EU SÓ NAMORO ‘TERRAPLANISTAS’ \\
\hline $\begin{array}{l}\text { An entirely fabricated } \\
\text { space exploration industry. } \\
\text { \#WeirdPlacesToHideMoney }\end{array}$ & T6 & 10.01.2019 & $\begin{array}{l}\text { Uma indústria de exploração } \\
\text { espacial totalmente fabricada. } \\
\text { \#LugaresEstranhosParaEsconderDinheiro }\end{array}$ \\
\hline $\begin{array}{l}\text { \#INeverLearnedHowTo blindly } \\
\text { and unquestioningly follow } \\
\text { propaganda. Damn. }\end{array}$ & T7 & 11.01 .2019 & $\begin{array}{l}\text { \#EuNuncaAprendia seguir cegamente e } \\
\text { inquestionavelmente a propaganda. Droga. }\end{array}$ \\
\hline $\begin{array}{l}\text { People's instinctive reaction } \\
\text { to confrontation is to engage } \\
\text { in fight-or-flight behavior. } \\
\text { Evolutionarily, this is well } \\
\text { justified, but that sort of siege } \\
\text { mentality is unhelpful to modern } \\
\text { discourse. }\end{array}$ & $\mathrm{T} 8$ & 12.04 .2019 & $\begin{array}{l}\text { A reação instintiva das pessoas ao } \\
\text { confronto é se envolver em comportamento } \\
\text { de luta-ou-fuga. Evolutivamente, isso é bem } \\
\text { justificado, mas esse tipo de mentalidade de } \\
\text { cerco é inútil para o discurso moderno. }\end{array}$ \\
\hline
\end{tabular}

Figura 1. O corpus analítico (continuação)

Fonte: Página do Twitter da Flat Earth Society 
Em T1 e T5, estão apresentados tweets de outubro e dezembro de 2018, respectivamente, classificados como "memes", que, como aponta Shifman (2013), são tipos de unidades informativas que se propagam eficientemente por meio da comunicação entre pessoas, sendo cada vez mais recorrentes na comunicação em meios digitais, utilizados por usuários para rápida absorção e disseminação de conteúdos. No primeiro desses, no rótulo de uma caixa de leite, está disposto um anúncio de "DESAPARECIDA", em referência à curvatura da Terra. Já o segundo desses traz uma frase estampada em uma camiseta utilizada por uma garota não identificada: "EU SÓ NAMORO TERRAPLANISTAS”.

A linguagem direta, bem como o sarcasmo, são características notáveis nas publicações da página e denotadas nos tweets T2 e T3. Nesses, por meio de frases curtas, a página reivindica, em T2, que "\#Todo mundo Deveria Ser informado sobre o simples fato de que a Terra é plana", e em T3, de que meramente "A Terra não é redonda". Essa estruturação curta das frases, além da utilização de uma hashtag, ferramenta utilizada para indexação de postagens em redes sociais, denotam o intuito dos criadores de conteúdo da Flat Earth Society de divulgar suas ideias de maneira ampla, dando a entender que as pessoas não estão bem informadas sobre o tema e que deveriam repensar em que estão acreditando. Essas características aparecem nas frases: "Se encontrar (a curvatura da Terra), contate TODO MUNDO" contida no "meme” em T1; “\#TodomundoDeveriaSer informado [...]”, contida em T2, e “\#RecomeçarEm5Palavras”, contida em T3.

Nesses casos citados, pode estar exemplificada a necessidade, por parte dos promotores da página da Flat Earth Society, de buscar consolidação discursiva, frente a uma possível segregação que lhes é imposta pela opinião pública e pela própria Ciência institucionalizada. Como parte de um grupo rotulado de maneira negativa no debate público - não se está aqui questionando o mérito disso -, nota-se, em suas publicações sobre a Terra Plana, a busca por afirmação de seus discursos, bem como a procura por desmoralização da autoridade da Ciência como meio de asserção de suas teses terraplanistas. Essa é uma ocorrência já debatida por Harambam e Aupers (2014), segundo os quais isto não necessariamente aponta para uma afronta, a qualquer custo, à Ciência moderna, mas indica uma espécie de busca por 'purificação' do que, segundo eles, seria o espírito livre e não dogmático de investigação do mundo.

Esse tipo de comportamento ambíguo frente à Ciência pode ser reiterado por T8. Neste, a página questiona o modo reativo como, em suposição, as pessoas costumam agir perante as teses da Terra Plana, assumindo, segundo afirma a página, comportamentos de luta ou de fuga em relação a ideias opostas ao que sabem. A página também indica que tal comportamento reativo tem justificativas evolutivas, além de ser, segundo sustentam, inútil ao discurso da Ciência moderna. Essa ambivalência frente aos conhecimentos científicos, em termos da crítica a um tipo de posicionamento autoritário de certos cientistas, pode ser equiparada à própria crítica que Feyerabend (1977) promoveu com relação ao ceticismo na Ciência. Para este autor, tal ceticismo:

[...] é mínimo; dirige-se contra a maneira de ver dos oponentes e contra ramificações 
secundárias das ideias fundamentais que se defende, mas nunca se levanta contra as próprias ideias básicas. Atacar ideias básicas desperta reações de tabu que não são menos intensas do que as reações de tabu nas chamadas sociedades primitivas. As crenças básicas são protegidas por essa reação e, como vimos, por elaborações secundárias; e tudo quanto deixa de acomodar-se ao estabelecido sistema de categorias é declarado incompatível com tal sistema ou é encarado como algo escandaloso ou, mais frequentemente, é simplesmente considerado como não existente (Feyerabend, 1977, p. 452, grifos do autor).

Além do ataque a ideias básicas por parte de uma Ciência com potencial autoritário, ao menos quando atua nos parâmetros citados, Feyerabend (1977) disserta ainda sobre a prática, por parte dessa Ciência, de desmoralização de discursos que não se adequam à hierarquia vigente, e passam a ser imbecilizados e estigmatizados no debate público. Disserta o autor:

Não se diz algumas pessoas acreditam que a Terra se move em torno do Sol, enquanto outras consideram que a Terra é uma esfera oca, onde se contém o Sol, os planetas, as estrelas fixas. Diz-se: a Terra gira em torno do Sol - e tudo o mais é pura idiotia (Feyerabend, 1977, p. 459, grifos do autor).

Nessa conjuntura, para Feyerabend (1977), esses mecanismos de segregação, que partem do ataque a ideias básicas e da desmoralização de oponentes, funcionariam como modos de afirmação das próprias teorias científicas, sem os quais seria impossível ter se dado o estabelecimento da Ciência moderna. Essa desmoralização do discurso rival, seja pelo ataque a ideias básicas, seja pela estigmatização dos discursantes, pode ser assemelhada aos princípios de exclusão sobre os quais dissertou Foucault (1996). Dentre eles, pode-se destacar a separação entre a razão e a loucura e entre o verdadeiro e o falso. Cita o autor, com relação ao primeiro princípio:

Desde a Idade Média, o louco é aquele cujo discurso não pode circular como o dos outros: pode ocorrer que sua palavra seja considerada nula e não seja acolhida, não tendo verdade nem importância [...]. Era através de suas palavras que se reconhecia a loucura do louco; elas eram o lugar onde se exercia a separação; mas não eram nunca recolhidas nem escutadas (Foucault, 1996, p. 11).

Para o autor, qualificar um discurso como atrelado à loucura sempre foi um meio de segregar os sujeitos que o proferem, ocorrência que ainda permanece ativa na sociedade. Atualmente, isto tem ocorrido por outros meios e de outras maneiras, mas com a mesma intenção de separação, em semelhança a outro princípio de exclusão que o autor denomina como vontade de verdade.

Ora, essa vontade de verdade, como os outros sistemas de exclusão, apoia-se sobre um suporte institucional: é ao mesmo tempo reforçada e reconduzida por todo um compacto conjunto de práticas como a pedagogia, é claro, como o sistema de livros, da edição de bibliotecas, como as sociedades de sábios outrora, os laboratórios hoje. Mas ela é também reconduzida, mais profundamente sem dúvida, pelo modo como o saber é aplicado em uma sociedade, como é valorizado, distribuído, repartido e de certo 
modo atribuído [...]. Enfim, creio que essa vontade de verdade assim apoiada sobre um suporte e uma distribuição institucional tende a exercer sobre os outros discursos - estou sempre falando de nossa sociedade - uma espécie de pressão e como que um poder de coerção (Foucault, 1996, p. 18).

Nesse contexto, pode-se considerar que a necessidade de afirmação e o tom provocativo, características dos tweets da Flat Earth Society, retratam uma espécie de reação dos promotores da página à segregação discursiva sofrida por 'terraplanistas', frente à predominância do discurso científico, ao menos neste âmbito. O que também pode ser entendido como uma tentativa de consolidação discursiva em face das qualificações negativas e estigmatizadas que eles recebem, considerações que podem ser apoiadas pelo que discutiram Harambam e Aupers (2014) sobre a busca, por parte de grupos conspiracionistas, por contestação da autoridade epistêmica da Ciência.

Deve-se deixar claro, a partir dessas aproximações teóricas, que não é nossa intenção colocar em xeque a legitimidade do estabelecimento do discurso científico, nem supor que discursos conspiracionistas possam ter coerência teórica e, em hipótese, mais espaço no debate público. Como aponta Latour (2004), ao se analisar uma controvérsia de um ponto de vista simétrico como este, sem qualificar, de antemão, como vencedores e vencidos os sujeitos envolvidos, corremos sempre o risco de sermos julgados como inimigos de uma Ciência em risco, ou de termos nossos discursos cooptados por sujeitos que os utilizem para atacar coisas que apreciamos.

Sabendo desse risco, a opção por sustentar esta discussão, nesses termos, se dá com o intuito de evitar, como apontaria Stengers (2015), o confronto pelo confronto, e acabar assim, conforme disserta a autora, propondo certezas sem que se vivencie a experiência da perplexidade. Em distanciamento a isso, a questão que propomos discutir está mais alinhada ao entendimento da complexidade cultural e discursiva da crença em conspirações, que pode estar associada a diversos fatores, entre eles, questões motivacionais e de necessidade de exclusividade, remarcadas por Lantian et al. (2017). Tais fatores vão além da demanda por domínio de conhecimentos científicos, com base em padrões de racionalidade, como destacaram Browne et al. (2015).

Essa complexidade cultural, atrelada à crença em conspirações, pode ser verificada ao analisarmos certos argumentos presentes nos tweets T4, T6 e T7. Para além de se oporem aos conhecimentos científicos estabelecidos sobre o formato da Terra, há também críticas referentes: à suposta doutrinação ideológica promovida pelo sistema escolar, no primeiro; à aplicação dos conhecimentos científicos pela indústria de exploração espacial e o grande volume de dinheiro envolvido, no segundo; bem como à suposta propaganda enganosa promovida pela Ciência na divulgação de suas teorias, no terceiro.

Bem mais do que uma defesa da hipótese da Terra Plana, essa diversidade temática, presente nas publicações da página, parece denotar uma tendência das conspirações se consolidarem como um sistema monológico de crenças, conforme discutido por Goertzel (1994) e Wood, Douglas e Sutton (2012). Tal sistema é dirigido não pela relação 
entre diferentes conspirações e suas teorizações particulares, mas pela coerência entre cada conspiração e uma crença de ordem superior sobre o mundo, que quase sempre se trata de um forte sentimento de desconfiança para com certas instituições ou grupos de pessoas. Essa conjuntura sustentaria o fato de que uma mesma pessoa pode acreditar e suportar diferentes conspirações que são desconexas contextualmente e até mesmo contraditórias entre si, pois o que as estaria conectando seria esse sentimento central de desconfiança e não a lógica ou a credulidade de suas hipóteses em particular.

Em termos discursivos, essa tendência de diversidade temática, presente nas publicações da página Flat Earth Society, remete à heterogeneidade do discurso sobre a qual disserta Foucault (1986). Isto significa considerar a formação de discursos como um sistema articulado, ou, como discute Fischer (2001) em relação à concepção foucaultiana de discurso em um contexto educacional, um espaço aberto de divergências e oposições, em que:

[...] a formação discursiva faz-se de asperezas e estridências, mais do que harmonias e superfícies lisas. Inteiramente vivo, o campo enunciativo acolhe novidades e imitações, blocos homogêneos de enunciados, bem como conjuntos díspares, mudanças e continuidades. Tudo nele se cruza, estabelece relações, promove interdependências. O que é dissonante também é produtivo, o que semeia a dúvida é também positividade crítica (Fischer, 2001, p. 210).

Pensar esse discurso, nesse âmbito, é considerar a desconfiança generalizada em relação aos conhecimentos científicos como a própria condição da possibilidade do discurso 'terraplanista', já que são as desavenças para com a Ciência que sustentam sua produção de enunciados. Esses que, para Foucault (1986), não são neutros, nem independentes, mas constituintes de uma rede em que cada enunciado individual desempenha algum papel em meio a outros, nesse campo de coexistências. Tais fatos nos auxiliam a compreender as publicações promovidas pela página Flat Earth Society como representações desses enunciados, o que está em consonância com as discussões realizadas por Goertzel (1994) e Wood, Douglas e Sutton (2012) sobre conspirações constituírem-se como um sistema monológico de crenças.

O que pode ser remarcado a partir dessa conjuntura é que, conforme destacado por Feyerabend (1977), a segregação de discursos rivais é o que propriamente dá escopo ao estabelecimento da Ciência na sociedade, assunção que pode ser associada com o que aborda Foucault (1996) em relação à institucionalização dos princípios de exclusão de discursos aqui discutidos. Em confrontação a isso, possivelmente por uma reação a essa segregação, a desconfiança generalizada em relação à Ciência pode ser considerada a condição do estabelecimento de discursos conspiracionistas como o da Terra Plana. Tais discursos buscam sustentação a partir da diversificação das temáticas por meio das quais procuram opor-se à Ciência, não ficando atrelados apenas às suas hipóteses 'terraplanistas', mas consolidando-se como parte de um sistema amplo de crenças.

De outra maneira, em se tratando da divulgação de suas hipóteses 'terraplanistas' em redes sociais, a heterogeneidade na formação de discursos, no âmbito de que discute 
Foucault (1986), tem como um dos efeitos a propagação de lutas por cooptação de sujeitos. Com essa pluralidade, o que cada vez mais está em jogo é uma "luta pela imposição de sentido, a luta entre vários discursos, na conquista de novos sujeitos” (Fischer, 2001, p. 212). Nesse contexto de disputa pelas mídias, convém destacar que:

[...] se cada discurso é remetido por ele mesmo a tantos outros, os discursos incorporados pela mídia, a partir de outros campos - mormente os da medicina, da pedagogia, da psicologia, da psicanálise -, também eles, ao entrarem na cena midiática, ao tomarem forma dentro desse campo específico da comunicação social, sofrem um tratamento que os retira de seu habitat e que, ao mesmo tempo, reforça a autoridade própria de cada um [...] (Fischer, 2012, p. 214, grifos do autor).

Essa conjuntura também parece valer para conspirações como a da Terra Plana. Em se tratando do ambiente das redes sociais, esses sujeitos podem disseminar seus discursos sem sofrerem, ao menos diretamente, a segregação institucionalizada discutida por Foucault (1996). Isto porque têm liberdade de publicação para compartilharem suas ideias, desde que não firam certas regras e políticas impostas pela plataforma. Esse ambiente representa então um meio potente pelo qual podem reforçar suas teses críticas à Ciência e cooptar mais sujeitos interessados em suas explanações, ainda que, em certos casos, sendo controversos ao utilizarem dos próprios conhecimentos científicos para tal, como ocorre em T8.

Nesse âmbito, a produção e o compartilhamento de conteúdo 'terraplanista' em uma rede social pela página Flat Earth Society constituem-se como a representação da formação prática de seu discurso. Isto é consonante com a perspectiva discursiva de Foucault (1996) e vai além das teorizações particulares que visam empreender, instituindo-se como parte de uma rede discursiva mais ampla do que significariam esses discursos em particular. Essas discussões nos levam a hipotetizar que a busca por exclusão desses discursos, bem como a tentativa forçada de mudança a partir de padrões absolutos de racionalidade, além de poderem ser indesejáveis em contextos democráticos de liberdade de expressão, são, em suma, incoerentes com a própria formação discursiva desses grupos, que têm no afrontamento à Ciência sua condição criadora e na contestação à autoridade científica um meio de reação à segregação que lhes é imposta².

Dito isso, o que esse panorama suscita é buscar o entendimento das ações de grupos 'terraplanistas', como no caso investigado, bem como da complexidade cultural à qual estão imersos, mais do que, de antemão, estabelecer soluções unívocas frente à expansão de suas teses na sociedade. Por outro lado, essas considerações não nos induzem a afirmar que não há nada a ser feito. Ao contrário, a própria proposição de estratégias, diante da expansão de crenças como essas, temerárias para contextos educacionais e científicos, precisa ter como fundamento a consideração da complexidade cultural e

2 Não está em questão o mérito dessa imposição, mas apenas que essa segregação discursiva é o que motiva tais reações. 
discursiva dessas crenças e não apenas suposições imediatas de demanda por domínio de conhecimentos científicos.

Enfim, diante deste movimento investigativo realizado e cujos resultados aqui expusemos, algumas possíveis considerações puderam ser propostas, de modo a dar fechamento a esta primeira parte da pesquisa (outras estão em curso).

\section{Possíveis considerações}

Ao término de uma pesquisa que procurou analisar publicações consideradas 'terraplanistas', oriundas de uma página de rede social, tomando como perspectivas de análise contribuições teóricas de Foucault (1996), Feyerabend (1977;2010), Latour (2004; 2011), Fischer (2001), dentre outras, algumas considerações puderam ser produzidas, de modo a tentar responder às questões norteadoras propostas: Sob essas óticas, que compreensões puderam ser demonstradas do discurso evidenciado nas publicações do Twitter analisadas, consideradas 'conspiracionistas' e que alegam que a Terra é plana? Que posicionamentos a área de Ensino de Ciências poderia arregimentar frente a esses discursos?

Com relação à primeira questão, as discussões realizadas permitem conjecturar que a formação de discursos conspiracionistas, como os que afirmam que a Terra é plana, tem como própria condição criadora a desconfiança da Ciência, ainda que com certa ambiguidade de intenções, como remarcado por Harambam e Aupers (2014).

Nesse sentido, frente à autoridade institucionalizada da Ciência na sociedade, a qual já foi discutida por Feyerabend (1977), e em consonância com os princípios de exclusão de discursos destacados por Foucault (1996), grupos 'terraplanistas', como o aqui investigado, têm reagido a essa autoridade como um meio de afirmação de seus próprios discursos. Isto nos leva a considerar que as justificativas para tais reações não estão atreladas somente a uma provável demanda por domínio de conhecimentos científicos, mas, como discutimos, constituem-se como modos de afirmação discursiva e de fortalecimento de suas próprias hipóteses. Isso não significa conjecturar que 'terraplanistas' não apresentem urgências por domínio de conhecimentos científicos ou por raciocínio baseado em evidências, mas apenas que esses não são, porventura, o fundamento único e talvez primordial da formação de seus discursos.

Nesse sentido, como parte do processo de afirmação discursiva, esses grupos têm buscado ampliar suas temáticas de discussão, não ficando subordinados somente às suas hipóteses 'terraplanistas', mas tecendo também críticas ao sistema escolar vigente, à aplicação dos conhecimentos científicos pela indústria de expansão espacial, bem como ao processo de divulgação científica na sociedade, como evidenciamos na análise de T4, T6 e T7. Assim, tais grupos se constituem parte de uma rede discursiva articulada (Foucault, 1996), caracterizada pela heterogeneidade na produção de enunciados que sustentam a formação de seu discurso. Tal assunção que pode ser equiparada às discussões promovidas por Goertzel (1994) e Wood, Douglas e Sutton (2012) com relação à característica das conspirações constituírem-se um sistema monológico de 
crenças, que tem, na desconfiança generalizada em relação à Ciência, seu meio agregador. Para além da formação discursiva, a explanação por meio de uma página em uma rede social também evidencia a busca por fortalecimento discursivo e por cooptação de mais sujeitos, como parte de um jogo de "luta pela imposição de sentido, a luta entre vários discursos, na conquista de novos sujeitos” (Fischer, 2001, p. 212).

Isso nos permite conjecturar sobre a segunda das questões norteadoras: dada a complexidade cultural e discursiva atrelada às conspirações, conceber que a coerção de exposições teóricas conspiratórias em meios midiáticos pode contribuir para sua interdição é uma ação tanto dogmática quanto potencialmente ingênua. Dogmática porque, conforme apontou Feyerabend (1977), partiria do ataque à maneira de ver o mundo de opositores, não sendo estimado e compreendido, desse modo, o enredamento no qual essas conspirações e suas atitudes de negação da Ciência estão submetidas, constituindo um sistema amplo e heterogêneo de crenças. Ingênua porque a condição primordial do estabelecimento desses discursos não é, porventura, a avaliação racional de fatos relacionados à determinada controvérsia, mas sim a própria desconfiança da Ciência. Dessa maneira, esperar que os caudatários das conspirações deixem de defender suas ideias, quando confrontados, seria confiar que eles renunciariam à sua própria condição de discursar, e que não buscariam outros meios de atuação se coagidos.

Essa assunção leva-nos à compreensão de que a proposição de estratégias de contenção, por parte da área de Ensino de Ciências, frente à expansão de conspirações como essas em seus contextos atuantes, não precisa ser pautada a partir de uma oposição frontal. Segundo Stengers (2015), tal prática deve ser evitada nos processos ao redor de uma controvérsia, uma vez que "esvazia o mundo e deixa subsistir apenas os dois campos visivelmente opostos, um funcionando em referência ao outro" (Stengers, 2015, p. 131). Além disso, necessita-se compreender essas conspirações em sua complexidade cultural e discursiva, o que ofereceria subsídios para conjecturar, tal como também indicam Harambam e Aupers (2014), sobre como e porque esses grupos têm resistido e combatido a autoridade institucionalizada da Ciência. Como dissertaram esses autores, há uma ambiguidade no posicionamento de grupos conspiratórios frente à Ciência, que ora é sacralizada por suas intenções, ora demonizada por seus meios de institucionalização. Nesse sentido, a oposição frontal, ao invés de auxiliar no entendimento desse posicionamento ambíguo, "ameaça dar respostas antes de ter aprendido a formular questões, propor certezas antes de ter feito a experiência da perplexidade" (Stengers, 2015, p. 27).

Essas considerações abrem margem para ampliar os caminhos investigativos da própria área de Ensino de Ciências, que demandará, nesses termos, do auxílio de teorias e técnicas de outras áreas do conhecimento, entre eles a Psicologia, a Psiquiatria, a Antropologia e a Sociologia, de maneira a abranger essa complexidade discutida, de forma que as estratégias para lidar com tais crenças conspiratórias possam estabelecerse de maneira sólida em termos teóricos e metodológicos. Não foi nossa intenção (neste movimento investigativo) apresentar soluções práticas ou métodos para lidar com essas 
conspirações, intenção esta que está em consonância com os próprios referenciais aqui utilizados. Todavia esperamos que as discussões promovidas possam fundamentar o desenvolvimento de mais pesquisas sobre esta temática, consolidando-a como relevante e frutífera para o Ensino de Ciências.

\section{Referências}

Bardin, L. (2011). Análise de conteúdo. Edições 70.

Browne, M., Thomson, P., Rockloff, M. J., \& Pennycook, G. (2015). Going against the herd: psychological and cultural factors underlying the 'vaccination confidence gap'. Plos One, 10(09), 1-14. Recuperado de https://doi.org/10.1371/journal.pone.0132562

Douglas, K. M., Sutton, R. M., Mitchell J. C., Rael, J. D., \& Annelie J. H. (2016). Someone is pulling the strings: hypersensitive agency detection and belief in conspiracy theories. Thinking \& Reasoning, 22(1), 57-77. Recuperado de http://dx.doi.org/10.1080/1354678 3.2015.1051586

Dunker, C., Tezza, C., Fuks, J., Tiburi, M., \& Safatle, V. (2017). Ética e pós-verdade. Dublinense.

Feyerabend, P. (1977). Contra o método. Francisco Alves.

Feyerabend, P. (2010). Adeus à razão. Editora Unesp.

Fischer, R. M. B. (2001). Foucault e análise do discurso em educação. Cadernos de Pesquisa, São Paulo, (114), 197-223. Recuperado de http://dx.doi.org/10.1590/S0100

Foucault, M. (1996). A ordem do discurso (3a. ed.). Edições Loyola.

Foucault, M. (1986). A arqueologia do saber. Forense.

Goertzel, T. (1994). Belief in conspiracy theories. Political psychology, 15(4), 731-742. Recuperado de https://doi.org/10.2307/3791630

Harambam, J., \& Aupers, S. (2014). Contesting epistemic authority: conspiracy theories on the boundaries of science. Public understanding of science, 24(4), 466-480. Recuperado de https://doi.org/ 10.1177/0963662514559891

Jolley, D., \& Douglas, K. M. (2014). The effects of anti-vaccine conspiracy theories on vaccination intentions. Plos one, 9(2), 1-9. Recuperado de https://doi.org/10.1371/ journal.pone.0089177

Lantian, A., Muller, D., Nurra, C., \& Douglas, K. M. (2017). I know thing they don't know: The role of need for uniqueness in belief in conspiracy theories. Social Psychology, 48(03), 160-173. Recuperado de https://doi.org/10.1027/1864-9335/a000306

Latour, B. (2004). Why has critique run out of steam? From matters of fact of matters of concern. Critical Inquiry, 30(2), 25-248. Recuperado de https://doi.org/10.1086/421123 
Latour, B. (2011). Ciência em ação: como seguir cientistas e engenheiros sociedade afora (2a. ed.). Editora Unesp.

Pelkmans, M., \& Machold, R. (2011). Conspiracy theories and their truth trajectories. Focaal - Journal of global and historical anthropology, (59), 66-80.

Prooijen, J. W. V., \& Douglas, K. M. (2018). Belief in conspiracy theories: basic principles of an emerging research domain. European journal of social psychology, 48(7), 897-908. Recuperado de https://doi.org/10.1002/ejsp.2530

Prooijen, J. W. V. (2015). Sometimes inclusion breeds suspicion: self-uncertainty and belongingness predict belief in conspiracy theories. European journal of social psychology. 46(3), 267-279. Recuperado de https://doi.org/10.1002/ejsp.2157

Prooijen, J. W. V. (2017). Why education predicts decreased belief in conspiracy theories. Applied cognitive psychology, 31(1), 50-58. Recuperado de https://doi.org/10.1002/ acp.3301

Prooijen, J. W. V., \& Douglas, K. M. (2018). Belief in conspiracy theories: basic principles of an emerging research domain. European journal of social psychology, 48(7), 897-908. Recuperado de https://doi.org/10.1002/ejsp.2530

Shifman, I. (2013). Memes in a digital world: reconciling with a conceptual troublemaker. Journal of computer-mediated communication, 18(3), 362-377. Recuperado de https:// doi.org/10.1111/jcc4.12013

Silva, B. C., Vegetti, F., \& Littvay, I. (2017). The elite is up to something: exploring the relation between populism and belief in conspiracy theories. Swiss political science review, 23(4), 423-443. Recuperado de https://doi.org/10.1111/spsr.12270

Stengers, I. (2015). No tempo das catástrofes: resistir à barbárie que se aproxima. Cosaf Naify.

Swami, V., Voracek, M., Stieger, S., Tran, U. S., \& Furnham, A. (2014). Analytic thinking reduces belief in conspiracy theories. Cognition, 133(3), 572-585. Recuperado de https:// doi.org/10.1016/j.cognition.2014.08.006

Wood, M. J. (2016). Some dare call it conspiracy: labeling something a conspiracy theory does not reduce belief in it. Political psychology, 37(5), 695-705. Recuperado de https:// doi.org/10.1111/pops.12285

Wood, M. J., Douglas, K. M., \& Sutton, R. M. (2012). Dead and alive: beliefs in contradictory conspiracy theories. Social psychological and personality science, 6(3), 767-773. Recuperado de https://doi.org/10.1177/1948550611434786 


\section{Leonardo Wilezelek Soares de Melo}

(ㄷ) https://orcid.org/0000-0002-4243-4216

Universidade Estadual de Londrina Programa de Pós-Graduação em Ensino de Ciências e Educação Matemática Londrina, Paraná, Brasil leonardowdemelo@gmail.com

Marinez Meneghello Passos

${ }^{\circledR}$ https://orcid.org/0000-0001-8856-5521

Universidade Estadual de Londrina

Programa de Pós-Graduação em Ensino de Ciências e Educação Matemática Departamento de Matemática/CCE Londrina, Paraná, Brasil marinezmp@sercomtel.com.br

\section{Rosana Figueiredo Salvi}

https://orcid.org/0000-0001-9475-9867

Universidade Estadual de Londrina

Programa de Pós-Graduação em Ensino de Ciências e Educação Matemática Departamento de Geociências/CCE Londrina, Paraná, Brasil ro06salvi@gmail.com

Submetido em 26 de fevereiro de 2020 Aceito em 09 de abril de 2020 Publicado em 01 de maio de 2020 